\title{
Efficacy of a School-Based Universal Program for Bullying Prevention: Considering the Extended Effects Associated with Achievement of the Direct Purposes of the Program
}

\author{
Katsuyuki Yamasaki ${ }^{1}$, Atsuko Umakoshi ${ }^{2}, \&$ Kanako Uchida ${ }^{1}$ \\ ${ }^{1}$ Department of Human Development, Naruto University of Education, Naruto-shi, Tokushima, Japan \\ ${ }^{2}$ Okinosu Elementary School, Tokushima-shi, Tokushima, Japan
}

Correspondence: Katsuyuki Yamasaki, Department of Human De velopment, Naruto University of Education, Naruto-shi, Tokushima, 772-8502, Japan.

Received: June 6, 2017

doi:10.11114/ijsss.v5i8.2534
Accepted: June 29, $2017 \quad$ Available online: July 13, 2017

URL: https://doi.org/10.11114/ijsss.v5i8.2534

\begin{abstract}
We have developed a group of universal prevention programs for children's health and adjustment. The programs are characterized by new theories such as the somatic-marker hypothesis and enjoyable methods that utilize animated stories and games. This study adopted one of the programs, a universal program for bullying prevention in third-grade students, and evaluated its efficacy. Participants were third-grade students in two public elementary schools in Japan. Homeroom classes in the schools were randomly divided into intervention and control groups. The final intervention group included 99 children ( 58 boys, 41 girls) and the final control group included 96 children ( 45 boys, 51 girls). The program was implemented weekly in one regular 45-minute class over eight weeks for all homeroom class members. Participants completed two questionnaires both before and after the program. Similar assessment periods were used for the control group. The questionnaires assessed the main purposes of the program (to enhance the understanding of bullying, to cultivate empathetic feelings for bullying victims, and to cultivate behavioral capabilities that stop bullying), and measured the adaptive status of children in homeroom class and at school. Results indicated that all of the main program purposes were achieved in the intervention group compared to the control group. Moreover, the level of the children's adjustment in homeroom class and at school significantly increased with the program, except for motivation for learning, which did not change. The necessity of future research that examines the sustainability of the efficacy of the program with randomized controlled trials is discussed, along with the study limitations.
\end{abstract}

Keywords: universal prevention program, bullying prevention, elementary school children, adjustment at school

\section{Introduction}

When a group of people forms, bullying often takes place. Specifically, fixed groups of children study and play together in small classrooms or playgrounds during a relatively long period of time in the school day. Moreover, children may be too immature to control their impetus for harming others when frustrated or provoked and to behave adaptively in human relationships. Bullying is a widespread problem in schools across the globe; thus, in many countries, bullying prevention programs have been developed and implemented. The first well-implemented and highly effective program was the Olweus Bullying Prevention Program (e.g., Olweus, 1993, 1994), which led to a plethora of new programs around the world. Additionally, the KiVa program that has been implemented in $>90 \%$ of schools in Finland has also been effective (e.g., Kärnä, Voeten, Little, Alanen, Poskiparta, \& Salmivalli, 2013; Salmivalli \& Poskiparta, 2012). Several other well-known programs in the United States, Austria, and Australia, such as Second Step (the Committee for Children, 1986), ViSC (Strohmeier, Hoffmann, Schiller, Stefanek, \& Spiel, 2012), and You Can Do It! (Bernard \& Hajzler, 1987), have also been developed and implemented, although most of them are not limited to bullying prevention.

Bullying has also been a serious problem in Japan, and is highly prevalent in schools, often triggering victims to commit suicide (see Klomek, Sourander, \& Gould, 2010 for a review). In response, the Japanese government enacted a law against bullying in 2013, and has aroused school personnel's attention to preventing byllying at school. Even before this law, school counselors were deployed in many schools in Japan starting in 1995. However, these attempts did not have 
any obvious efficacy. Prior attempts primarily aimed to resolve problems after bullying occurred, rather than focusing on prevention. Although many researchers and teachers assume that bullying prevention is more crucial and easier to conduct than managing it after it occurs, no reliable prevention programs that could be implemented on a regular basis at school have been developed in Japan. Additionally, the Japanese education system is very different from those in western countries, so the extant bullying prevention programs developed elsewhere cannot be applied to schools in Japan. For instance, the curricula in Japanese schools are more inflexible and consist of more classes per day than in most western countries.

In consideration of the present educational system and conditions in Japan, a group of new school-wide universal prevention programs for children's health and adjustment have been de veloped. Together, the programs are called "TOP SELF (Trial of Prevention School Education for Life and Friendship)" and consist of two types of prevention programs: comprehensive base programs and optional programs. TOP SELF includes many evidence-based programs rooted in scientific theories and methods (see Uchida, Yamasaki, \& Sasaki, 2014; Yamasaki, Murakami, Yokoshima, \& Uchida, 2015 for details). Of these two types, the optional programs aim to prevent specific problems such as bullying, school truancy, and violence. The current paper describes the bullying prevention program.

Table 1. Hierarchical Structure of the Purposes in the Bullying Prevention Program

\begin{tabular}{|c|c|c|c|c|}
\hline & Intermediate purposes & Subordinate purposes & Operational purposes & $\begin{array}{l}\text { Class } \\
\text { order }\end{array}$ \\
\hline I. & $\begin{array}{l}\text { To enhance the } \\
\text { understanding of } \\
\text { bullying }\end{array}$ & $\begin{array}{l}\text { 1. To understand bullying and } \\
\text { its damage } \\
\text { 2. To understand perpetration } \\
\text { of bullying and bullying } \\
\text { bystanding }\end{array}$ & $\begin{array}{l}\text { a. To understand what bullying is } \\
\text { b. To understand the damage bullying victims incur } \\
\text { c. To understand the damage bullies receive } \\
\text { d. To understand the damage bullying bystanders } \\
\text { receive } \\
\text { e. To understand that bystanding encourages } \\
\text { bullying }\end{array}$ & 1 \\
\hline \multirow[t]{3}{*}{ II. } & $\begin{array}{l}\text { To cultivate empathetic } \\
\text { feelings for bullying } \\
\text { victims }\end{array}$ & 3. To cultivate empathy & $\begin{array}{l}\text { f. To notice and understand bullying victims' } \\
\text { distress } \\
\text { g. To imagine bullying victims' feelings and evoke } \\
\text { identical feelings }\end{array}$ & 2 \\
\hline & & 4. To cultivate sympathy & $\begin{array}{l}\text { h. To understand the importance of sympathy and } \\
\text { the differences between empathy and sympathy }\end{array}$ & 3 \\
\hline & & & $\begin{array}{l}\text { i. To evoke sympathy toward bullying victims and } \\
\text { other distressed people }\end{array}$ & 4 \\
\hline \multirow[t]{4}{*}{ III. } & $\begin{array}{l}\text { To cultivate capabilities } \\
\text { that stop bullying }\end{array}$ & $\begin{array}{l}\text { 5. To learn the factors leading } \\
\text { to bullying bystanding }\end{array}$ & $\begin{array}{l}\text { j. To learn the causes leading to bullying bystanding } \\
\text { (diffusion of responsibility, evaluation } \\
\text { apprehension, and pluralistic ignorance) } \\
\text { k. To learn how to think to avoid bullying } \\
\text { bystanding }\end{array}$ & 5 \\
\hline & & $\begin{array}{l}\text { 6. To learn and conduct } \\
\text { behaviors to support bullying } \\
\text { victims }\end{array}$ & $\begin{array}{l}\text { 1. To learn various helping behaviors (emotional } \\
\text { support, collaboration for problem solving, and } \\
\text { assertion) }\end{array}$ & 6 \\
\hline & & & m. To select and conduct helping behaviors & 7 \\
\hline & & & Review of the prior classes & 8 \\
\hline
\end{tabular}

The bullying prevention program that has been implemented for third- or fourth-grade elementary school students is conducted during eight 45-minute classes. The purposes of this program are hierarchically structured, and each class includes several operational purposes (Table 1). These purposes were established based on empirical scientific data regarding the factors that cause children to become bullies or bystanders (see Yamasaki, 2016 for details). Briefly, the purposes are divided into three sets: cognition (knowing what bullying and bystanding are), feelings (feeling empathy and sympathy for victims), and behaviors (helping victims [without bystanding]). The background theories of TOP SELF (see Uchida et al., 2014) are applied to this bullying prevention program. Briefly, cognition, feelings, and behaviors are appropriately learned and memorized only in combination with emotions, which are primarily unconscious physiological reactions as suggested by the somatic-marker hypothesis (Damasio, 1994, 2003). According to this hypothesis, emotions become markers for making decisions that include cognition and behaviors, which suggests that without appropriate emotional evocation, we cannot make any decisions. Thus, it is postulated that good learning of new psychological characteristics could occur concurrently with emotions. That is, long-term learning will not occur if sufficient emotions are not evoked. Thus, based on this theory, the purposes of the program are achieved by using methods that evoke emotions.

Like the other programs in TOP SELF, the bullying prevention program follows the standard class procedure (see Table 2 and Uchida et al., 2014 for details). In Japan, one class lasts for 45 minutes in elementary schools, and almost all 
classes are provided in the same homerooms with the same classmates ( $<40$ students). The class procedure includes various methods, such as animated stories and climax activities in which enjoyable games and other activities are employed. As stated above, based on the theories of TOP SELF, these methods evoke emotions while educational objectives are learned.

The aim of the present study was to examine the efficacy of the TOP SELF bullying prevention program in third-grade elementary school students. In addition to the assessment of the main purposes of the program, extended efficacy, such as adaptive status in homeroom class and at school that would be observed if the objectives were achieved, was also evaluated. Efficacy was evaluated by comparing intervention and control groups.

Table 2. TOP SELF Standard Class Procedure

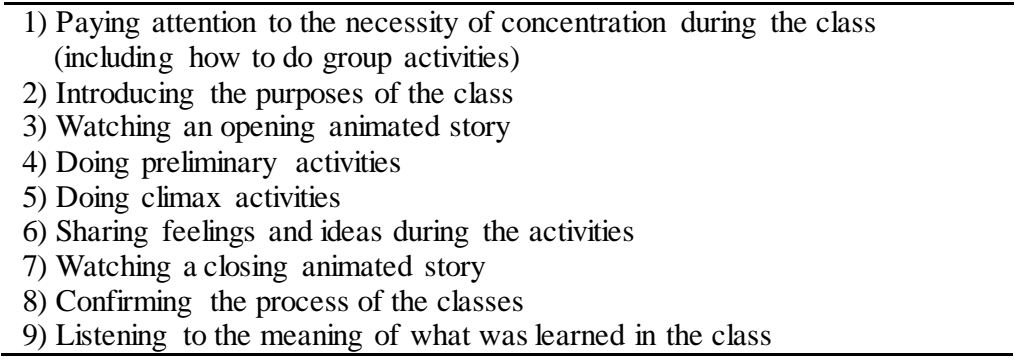

\section{Method}

\subsection{Participants}

The participants were third-grade students in two public elementary schools in a suburb of the capital city of Tokushima prefecture in Japan. Homeroom classes were randomly divided into intervention ( $\mathrm{n}=3$ classes) and control ( $\mathrm{n}=3$ classes) groups. After eliminating children $(\mathrm{n}=9)$ for data analyses due to absence from school on the evaluation days or missing data, the final intervention group included 99 children (58 boys, 41 girls) and the final control group included 96 children ( 45 boys, 51 girls). Although the control group was originally defined as a wait-list group, the school principals did not ask for any intervention due to abrupt schedule changes in the school curricula.

\subsection{Procedure}

In the intervention group, the first evaluation was conducted in homeroom classes about 1 month before the start of the program. The second evaluation was performed in the 2 days before the start of the program. The third evaluation was conducted 1 day after the last program class. Data from the first evaluation are not reported in this paper due to another purpose of the study. Participants in the control group were subjected to the second and third evaluations around the same time periods as participants in the intervention group. For each evaluation, all participants completed two questionnaires, along with two question items regarding the enjoyableness and intelligibility of the program that were administered only during the third evaluation. These questionnaires are shown in the measure section below.

The current program was implemented weekly for eight successive weeks in regular 45-minute classes for all homeroom class members. Each class proceeded according to the TOP SELF standard class procedure (Table 2). Briefly, the standard procedure has the following characteristics (see Uchida et al., 2014 for details): Every class strongly engages children so that they can focus on class activities in which animated stories, games, enjoyable competition, etc. are included. Thus, children evoke emotions and feelings during classes, with which desirable cognitive and behavioral characteristics are simultaneously learned; the emotions and feelings associated with the learned characteristics are stored as memories. If the learning is successful, the memories are extracted as guided by the associated emotions and feelings, leading to the application of the stored cognition, thoughts, and behaviors to real life when needed. The intervention group took regular classes in addition to this program during the period of the program implementation, while the control groups took the same regular classes during the same period without the program.

The program and evaluation were given as official school classes primarily by school teachers under the supervision of the principals. Before the start of the study, the authors explained about the details of the program and research to the principals and homeroom teachers who implement the program. After their permission for the execution of the program and research was obtained, the teachers delivered the documents describing the program and research to the children's guardians via their children. No guardians refused to have their children participate in the program and research.

\subsection{Measures}

Main (intermediate) purposes of the program. As shown in Table 1, the program has three main (intermediate) purposes 
(I-III), through which children's changes are assessed to evaluate efficacy. The Scale of the Factors of Bullying Prevention for Children (SFBP-C), which was developed by three psychologists with PhDs who were familiar with the concepts measured, thereby providing content validity to the scale, was used for this aim. The SFBP-C includes three subscales, each of which assesses one of the three main purposes with four question items. Example items include "Do you know what bullying is?" for Purpose I, "Can you guess the feelings of bullied children?" for Purpose II, and "Can you think about how to stop bullying?" for Purpose III. Children ans wered on a 4-point Likert scale (e.g., 1 = "don't think so at all" to $4=$ "think so very much"). For scoring each subscale, the scores for four items are summed, giving score range of 4 through 16. Additionally, the composite score was calculated by summing the scores of the three subscales. In this study, the alpha of the composite score was high (.85), and those of the three subscales were within allowable limits (.64 to .81 ) for each subscale. In addition, children were asked about their class members overall, but only one item modified from the above four question items was employed for each purpose. The composite score summing the three scores of the subscales was also employed ( $\alpha=.79$ in this study).

Adaptive status in homeroom class and at school. If the main purposes are achieved by this program, it is predicted that the efficacy of the program would extend to children's adaptive status in homeroom class and at school. Extended efficacy was examined using a questionnaire called "the Questionnaire-Utilities (Q-U)" (Kawamura \& Tagami, 1997). The Q-U includes five factors: approval, aggrievedness, peer relationship, motivation for learning, and classroom climate. Item examples include "Do your classmates encourage you when you fail to do something?" for approval, "Have you experienced hardship due to violence by your classmates?" for aggrievedness, "Do your classmates talk to you and respect you?" for peer relationship, "Do you feel happy when you achieve things you previously could not?" for motivation for learning, and "Do you think your homeroom members are cooperative and generally get along with each other?" for classroom climate. Children answered on a 4-point Likert scale (e.g., $1=$ "don't think so at all" to $4=$ "think so very much"). For scoring each subscale, the scores of 3 or 6 question items are summed, resulting in a score range of 3-9 for peer relationship, motivation for leaning, and classroom climate, and 6-24 for approval and aggrievedness. The validity and reliability of the scale were confirmed by Kawamura and Tagami (1997). The alphas in this study were $.82, .80, .72, .60$, and .73 for approval, aggrievedness, peer relationship, motivation for learning, and classroom climate, respectively. Among the five factors, aggrievedness is the most directly related to being bullied.

Enjoyment and intelligibility of the program for children. As an additional measure, the enjoyment and understanding of the program by participating children was measured by two question items: "Did you enjoy the classes?" and "Did you understand the contents of the classes?," respectively. Children answered on a 5-point Likert scales from "not at all" to "very much."

Table 3. Mean Scores (Standard Deviations) of the Subscales of the Scale of the Factors of Bullying Prevention for Children (SFBP-C) for Oneself for Each Sex and Period in the Intervention and Control Groups

\begin{tabular}{|c|c|c|c|c|c|c|c|c|c|}
\hline \multirow{3}{*}{$\begin{array}{l}\text { Variables } \\
\text { Purpose I }\end{array}$} & \multirow[b]{2}{*}{ Groups } & \multicolumn{4}{|l|}{ Boys } & \multicolumn{4}{|l|}{ Girls } \\
\hline & & \multicolumn{2}{|c|}{$\begin{array}{l}\text { Pre- } \\
\text { intervention }\end{array}$} & \multicolumn{2}{|c|}{$\begin{array}{l}\text { Post- } \\
\text { intervention }\end{array}$} & \multicolumn{2}{|c|}{$\begin{array}{l}\text { Pre- } \\
\text { intervention }\end{array}$} & \multicolumn{2}{|c|}{$\begin{array}{l}\text { Post- } \\
\text { intervention }\end{array}$} \\
\hline & Intervention Group & 13.26 & $(2.16)$ & 14.76 & $(1.56)$ & 13.39 & $(2.02)$ & 15.41 & $(.87)$ \\
\hline & Control Group & 12.96 & (1.67) & 13.02 & (1.83) & 13.28 & (1.54) & 13.55 & (1.45) \\
\hline \multirow[t]{2}{*}{ Purpose II } & Intervention Group & 13.62 & $(2.42)$ & 14.56 & $(1.60)$ & 14.41 & $(2.20)$ & 15.20 & $(1.35)$ \\
\hline & Control Group & 13.24 & (1.17) & 12.75 & (2.44) & 14.24 & (1.66) & 13.82 & (1.58) \\
\hline \multirow[t]{2}{*}{ Purpose III } & Intervention Group & 12.12 & $(2.53)$ & 13.41 & $(2.02)$ & 12.49 & $(2.40)$ & 14.53 & (1.57) \\
\hline & Control Group & 10.73 & $(2.32)$ & 10.53 & (2.89) & 11.78 & $(2.11)$ & 11.90 & $(2.31)$ \\
\hline Total Composite & Intervention Group & 39.00 & (6.34) & 42.72 & $(4.45)$ & 40.29 & $(5.95)$ & 45.15 & $(2.84)$ \\
\hline Score & Control Group & 38.81 & $(5.18)$ & 39.00 & (6.34) & 40.44 & $(5.91)$ & 40.29 & $(5.95)$ \\
\hline
\end{tabular}

\section{Results}

\subsection{Effects of the Program on the Main Purposes}

Table 3 shows the mean subscale scores of the SFBP-C for oneself in each of the groups and periods for boys and girls. Data were analyzed by 2 (intervention and control groups) x 2 (pre-intervention and post-intervention periods) x 2 (boys and girls) analyses of variance (ANOVA). In describing the results, we focused on the interactive effects of (group $x$ period) and (group $x$ period $x$ sex), because the efficacy of the program can best be examined in such interactions. The results revealed that the (group x period) interaction was significant on all subscales $(F \mathrm{~s}(1,191)=32.01,24.24,28.00$, and 39.41 for Purposes I to III and the composite score, respectively; $p<.001$ for all). No significant interaction was observed for (group x period x sex). 
Table 4. Mean Scores (Standard Deviations) of the Subscales of the Scale of the Factors of Bullying Prevention for Children (SFBP-C) for Others for Each Sex and Period in the Intervention and Control Groups

\begin{tabular}{|c|c|c|c|c|c|c|c|c|c|}
\hline \multirow{3}{*}{$\begin{array}{l}\text { Variables } \\
\text { Purpose I }\end{array}$} & \multirow{4}{*}{$\begin{array}{l}\text { Groups } \\
\text { Intervention Group } \\
\text { Control Group }\end{array}$} & \multicolumn{4}{|c|}{ Boys } & \multicolumn{4}{|c|}{ Girls } \\
\hline & & \multicolumn{2}{|c|}{$\begin{array}{l}\text { Pre- } \\
\text { intervention }\end{array}$} & \multicolumn{2}{|c|}{$\begin{array}{l}\text { Post- } \\
\text { intervention }\end{array}$} & \multicolumn{2}{|c|}{$\begin{array}{l}\text { Pre- } \\
\text { intervention }\end{array}$} & \multicolumn{2}{|c|}{$\begin{array}{l}\text { Post- } \\
\text { intervention }\end{array}$} \\
\hline & & 3.90 & $(1.00)$ & 4.43 & $(.86)$ & 4.00 & $(.90)$ & 4.39 & $(.77)$ \\
\hline & & 3.89 & (1.01) & 3.76 & (1.09) & 3.78 & $(.76)$ & 3.78 & $(.86)$ \\
\hline \multirow[t]{2}{*}{ Purpose II } & Intervention Group & 4.09 & $(1.00)$ & 4.19 & $(.96)$ & 4.12 & $(.98)$ & 4.49 & $(.81)$ \\
\hline & Control Group & 4.02 & $(.94)$ & 3.76 & (1.09) & 4.06 & $(.86)$ & 3.78 & $(.86)$ \\
\hline \multirow[t]{2}{*}{ Purpose III } & Intervention Group & 3.90 & $(1.15)$ & 4.10 & (1.19) & 3.85 & (1.03) & 4.46 & $(.75)$ \\
\hline & Control Group & 3.64 & (1.21) & 3.49 & $(1.25)$ & 3.69 & (1.09) & 3.57 & (1.01) \\
\hline Total Composite & Intervention Group & 11.88 & (2.64) & 12.71 & $(2.60)$ & 11.98 & $(2.48)$ & 13.32 & $(1.75)$ \\
\hline Score & Control Group & 11.56 & $(2.54)$ & 10.93 & $(2.61)$ & 11.53 & $(2.24)$ & 10.93 & $(2.36)$ \\
\hline
\end{tabular}

Table 5. Mean Scores (Standard Deviations) of the Subscales of Questionnaire-Utilities (Q-U) for Each Sex and Period in the Intervention and Control Groups

\begin{tabular}{|c|c|c|c|c|c|c|c|c|c|}
\hline \multirow{3}{*}{$\begin{array}{l}\text { Variables } \\
\text { Peer relationship }\end{array}$} & \multirow{4}{*}{$\begin{array}{l}\text { Groups } \\
\text { Intervention Group } \\
\text { Control Group }\end{array}$} & \multicolumn{4}{|l|}{ Boys } & \multicolumn{4}{|l|}{ Girls } \\
\hline & & \multicolumn{2}{|c|}{$\begin{array}{l}\text { Pre- } \\
\text { intervention }\end{array}$} & \multicolumn{2}{|c|}{$\begin{array}{l}\text { Post- } \\
\text { intervention }\end{array}$} & \multicolumn{2}{|c|}{$\begin{array}{l}\text { Pre- } \\
\text { intervention }\end{array}$} & \multicolumn{2}{|c|}{$\begin{array}{l}\text { Post- } \\
\text { intervention }\end{array}$} \\
\hline & & 9.47 & $(1.86)$ & 9.69 & $(1.78)$ & 9.98 & $(1.86)$ & 10.00 & $(1.79)$ \\
\hline & & 9.67 & $(1.51)$ & 9.18 & (1.64) & 9.90 & $(1.24)$ & 9.63 & $(1.52)$ \\
\hline \multirow{2}{*}{$\begin{array}{l}\text { Motivation for } \\
\text { learning }\end{array}$} & Intervention Group & 9.93 & $(1.88)$ & 10.14 & $(1.65)$ & 10.29 & (1.54) & 10.61 & $(1.34)$ \\
\hline & Control Group & 9.31 & $(2.55)$ & 8.98 & $(2.28)$ & 9.98 & (1.91) & 10.10 & $(1.72)$ \\
\hline \multirow{2}{*}{ Classroom climate } & Intervention Group & 10.34 & $(1.84)$ & 10.67 & $(1.50)$ & 10.78 & $(1.59)$ & 10.93 & $(1.68)$ \\
\hline & Control Group & 10.31 & $(1.46)$ & 10.00 & $(1.45)$ & 10.86 & (1.18) & 10.61 & $(1.25)$ \\
\hline \multirow[t]{2}{*}{ Approval } & Intervention Group & 17.86 & (4.03) & 18.33 & $(3.80)$ & 18.49 & (3.34) & 19.15 & $(3.59)$ \\
\hline & Control Group & 18.05 & $(3.47)$ & 16.16 & $(3.65)$ & 18.51 & $(2.97)$ & 18.36 & $(3.34)$ \\
\hline \multirow[t]{2}{*}{ Aggrievedness } & Intervention Group & 13.22 & $(4.60)$ & 11.86 & $(3.76)$ & 11.00 & $(3.50)$ & 10.61 & $(2.85)$ \\
\hline & Control Group & 13.60 & $(4.23)$ & 13.82 & $(4.53)$ & 13.10 & $(4.43)$ & 13.08 & (4.63) \\
\hline
\end{tabular}

Post hoc tests with Bonferroni corrections using the data collapsed across boys and girls showed that the scores for the Purpose I and III subscales significantly increased from the pre-intervention to post-intervention periods in the intervention group, while no significant changes were observed in the control group. Moreover, the scores for the Purpose II subscale and the composite score significantly increased from the pre-intervention to post-intervention periods in the intervention group, while scores significantly decreased in the control group. These results show that the program was effective in enhancing the cognitive, emotional, and behavioral components to prevent bullying and bystanding as measured by self-reports.

Table 4 shows the mean scores for the SFBP-C subscales regarding the other class members (i.e., the entire class) in each of the groups and periods for boys and girls. A significant (group x period) interaction was observed for all subscales $(F \mathrm{~s}(1,191)=19.51, p<.001 ; 10.63, p<.05 ; 10.73, p<.01$; and 23.33, $p<.001$ for Purposes I, II, and III, and the composite score, respectively). No significant interaction was observed for (group x period x sex).

Post hoc tests with Bonferroni corrections using the data collapsed across boys and girls showed that the scores for Purposes I, II, III, and the composite score significantly increased from the pre-intervention to post- intervention periods in the intervention group, while in the control group, the scores for Purposes I and III and the composite score did not significantly change from the pre-intervention to post-intervention periods, and the scores for Purpose II significantly decreased during the same period. These results show that the program effectively enhanced the cognitive, emotional, and behavioral components to prevent bullying and bystanding with respect to self-reports of the other class members.

\subsection{Extended Effects Associated with Achievement of the Main Purposes}

Table 5 shows the mean Q-U subscale scores in each of the groups and periods for boys and girls. The (group x period) interaction was significant for all subscales $(F \mathrm{~s}(1,191)=7.09, p<.01 ; 7.30, p<.01 ; 9.22, p<.01 ; 14.50, p<.01$; and 4.76 , 
$p<.05$ for peer relationship, classroom climate, approval, and aggrievedness, respectively), except for motivation for learning $(F(1,191)=2.63, p>.05$ ). No significant (group x period $\mathrm{x} \mathrm{sex}$ ) interaction was observed. Regarding the (group $\mathrm{x}$ period) interactions, post hoc tests with Bonferroni corrections using the data collapsed across boys and girls showed that the scores of peer relationship, classroom climate, and approval significantly decreased from the pre-intervention to post-intervention periods in the control group, while no significant change was observed in the intervention group, and that the aggrievedness scores significantly increased during the same period in the intervention group, with no significant change in the control group. These results reveal that the program had extended efficacy (except for motivation for learning) into a more adaptive status in homeroom class and at school, which is associated with achievement of the main purposes.

Finally, the extent to which children enjoyed and understood the classes was very high (Table 6). Overall, 98\% of the children enjoyed the classes either "pretty much" or "very much," and 96\% understood the classes either "pretty well" or "very well."

Table 6. Percentages of Each Answer Choice in the Questionnaire for Enjoyment and Intelligibility of the Program

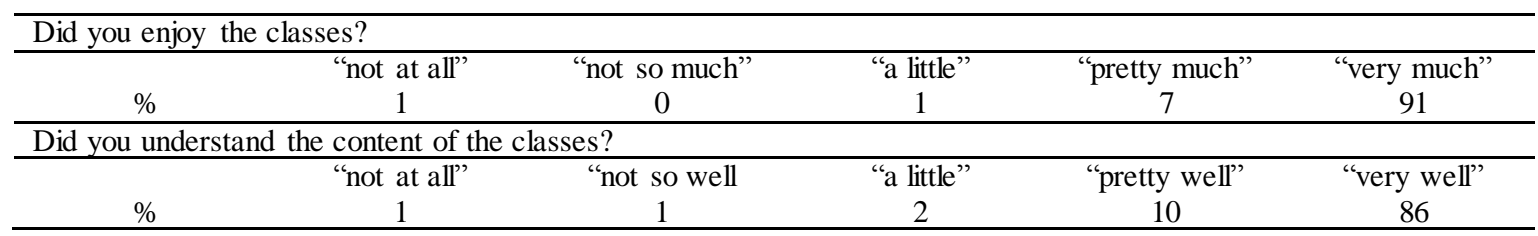

\section{Discussion}

The current bullying prevention program differs from other extant programs in that its background theories underscore subconscious functions and its attractiveness for children is very high. This study examined the effects of the program in third-grade elementary school students in Japan. The results showed that this program significantly enhanced the scores regarding the three main purposes of the program in terms of both self and homeroom class mates as assessed by each participant. Additionally, the adaptive status in homeroom class and at school that was measured as an extended effect of the program was improved, except with respect to motivation for learning.

According to the hierarchical educational purposes, the current program aimed to enhance adaptive cognitive, emotional, and behavioral components to prevent bullying and bystanding behaviors. The program was effective in that these three components improved, which led to a decrease in bullying, as shown in the aggrievedness score of the Q-U. Moreover, the self-report questionnaires that were utilized to assess the main purposes of the program were administered not only for participants to assess themselves, but also to assess their homeroom classmates. Inclusion of these two types of assessments underscores the efficacy of the program.

In addition, the improved characteristics concerning the main purposes appear to lead to better peer relationships and adaptation in classrooms and at school. This finding was predictable, because the main purposes of the programs per se are associated with the psychological characteristics required for good peer relationships. Moreover, the finding that the children enjoyed the program is crucial in school education, because children's enjoyment means that they are absorbed in the classes. This absorption is needed to ensure the success not only of this program but also for any program or school subject. In recent years, an increasing proportion of children are not engaging in their school classes, because most classes bore them. Classes are the most important element of school for children, and lack of interest often leads to various behavioral problems, including bullying, school truancy, and drug use. The current program includes many educational components and methods, such as games, exercises, animations, and music, making it difficult for teachers to successfully conduct the program without extensive practice. However, fascinating and meaningful classes always include extensive preparation, necessitating that teachers receive high-quality training to successfully run the classes.

This study has several limitations. First, the present assignment of intervention and control groups differs from that for randomized controlled trials (RCTs); assignments were not random. In addition, the numbers of schools and classes were small. Moreover, the units for statistical analyses are ideally recommended to be schools rather than individual children (Edmundson et al., 1995). However, significant costs and labor are required to conduct RCTs. Second, the sustainability of the efficacy of the program needs to be tested, as the current study only examined the efficacy just after the program. It is highly predictable that the efficacy would not last for long, because the program was implemented only over the course of 8 hours. Thus, some booster sessions or periodically repeated programs that differ from the present program in terms of the methodological content of the classes even if the purposes are similar are required. Third, the measure utilized to assess the main purposes in this study only includes the content validity; the measure also needs to be examined with respect to construct validity, e.g., in terms of criterion-related or predictive validities. 
Moreover, we must note that the present measures were all consciously answered by children. As the theories of the current program emphasize subconsciousness and unconsciousness functions, we need to also use some measures that can assess nonconscious status. Additionally, self-report answers can be distorted by socially desired responses, such as self-deception and impression management (Paulhus, 1984). However, projective methods such as the Rorschach and Thematic Apperception Tests are difficult to apply to a large number of children such as those in schools, because they are individually administered over a long time and include subjective and laborious assessment methods.

In recent years, implicit psychological characteristics have started to be assessed utilizing various implicit association tests (Greenwald \& Banaji, 1995). The implicit characteristics are a preconscious representation of one's psychological functions such as affect, self-esteem, and various other personalities and attitudes. In TOP SELF's other programs, implicit affect has been used in the Implicit Positive and Negative Affect Test for Children (Uchida, Fukuda, \& Yamasaki, 2014); moreover, an implicit self-esteem test has also been developed (Yokoshima, Uchiyama, Uchida, \& Yamasaki, 2017), which has just started to be used in the assessment of TOP SELF. Thus, it is highly expected that in the bullying prevention program, the assessment should be extended to measuring nonconscious status using some implicit measures.

The current study results suggest future promising research avenues. Regarding the program per se, it should be broadened to cover programs for children in both lower and higher grades. Specifically, programs for much younger children should be developed, because the characteristics leading to bullying and bystanding are more easily modifiable or even preventable in early childhood. Moreover, the program should be extended to including components outside of school (particularly at home). Parental child-rearing attitudes may form most of the psychological characteristics that lead to bullying and bystanding. For example, relational aggression, such as the circulation of malicious rumors, as a bullying behavior that is evoked to break human relationships is partially formed through parental child-rearing attitudes (e.g., Casas, Weigel, Crick, Ostrov, Woods, Yeh, \& Huddleston-Casas, 2006; Hart, Nelson, Robinson, Olsen, \& McNeilly-Choqaue, 1998).

Current education systems overemphasize academics, resulting in the allocation of too little time and labor for resolution of bullying problems. The Social and Emotional Learning (SEL) prevention program has been shown to be positively associated with academic performance (Caprara, Barbaranelli, Pastorelli, Bandura, \& Zmbardo, 2000; Wang, Haertal, \& Wallberg, 1997). To fundamentally enhance academic performance, various emotional and social characteristics are required. The current program as well as the SEL program is associated with the enhancement of such characteristics with respect to cognitive, emotional, and behavioral components. Academics are important, but learning how to live a healthy and adaptive life is more important for children. Education needs to turn sharply to these more critical aspects of education. And it is expected that this program will be implemented on a regular basis at school.

\section{Conclusion}

The current universal program for bullying prevention is effective in improving the cognitive, emotional, and behavioral factors that lead to bullying and bystanding. Moreover, the program includes strong motivational power that attracts children, resulting in their absorption in the program. This motivational factor is essential, because unless children are engaged in the program, it will not be effective even if the methodological content is well-developed. This kind of program needs to be conducted on a regular basis at school so that long-lasting efficacy can be acquired. Although school curricula are inflexible in Japan, underscoring the emphasis on academics, school stakeholders should note that children's well-being, including health and social adjustment, is more crucial than academics. As bullying is prevalent in many countries, resulting in distress to victims and surrounding children, people involved in school education need to consider this warning seriously.

\section{Acknowledgements}

This research was supported by a grant from the Japan Society of the Promotion of Science (No. 24530872).

\section{References}

Bernard, M. E., \& Hajzler, D. J. (1987). You can do it! What every student (and parent) should know about achieving success at school and in life. Melbourne, VIC. Australia: Collins Dove.

Caprara, G. V., Barbaranelli, C., Pastorelli, C., Bandura, A., \& Zimbardo, P. G. (2000). Prosocial foundations of children's academic achievement. Psychological Science, 11, 302-306. https://doi.org/10.1111/1467-9280.00260

Casas, J. F., Weigel, S. M., Crick, N. R., Ostrov, J. M., Woods, K. E., Yeh, E. A. J., \& Huddleston-Casas, C. A. (2006). Early parenting and children's relational and physical aggression in the preschool and home contexts. Applied Developmental Psychology, 27, 209-227. https://doi.org/10.1016/j.appdev.2006.02.003

Damasio, A. R. (1994). Descartes' error: Emotion, reason, and the human brain. New York: Putnam.

Damasio, A. R. (2003). Looking for Spinoza: Joy, sorrow and the feeling brain. New York: Harcourt. 
Greenwald, A. G., \& Banaji, M. R. (1995). Implicit social cognition: Attitudes, self-esteem, and stereotypes. Psychological Review, 102, 4-27. https://doi.org/10.1037/0033-295X.102.1.4

Hart, C. H., Nelson, D. A., Robinson, C. C., Olsen, S. F., \& McNeilly-Choque, M. K. (1998). Overt and relational aggression in Russian Nursery-school-age children: Parenting style and marital linkages. Developmental Psychology, 34, 687-697.https://doi.org/10.1037/0012-1649.34.4.687

Kärnä, A., Voeten, M., Little, T. D., Alanen, E., Poskiparta, E., \& Salmivalli, C. (2013). Effectiveness of the KiVa Antibullying Program: Grades 1-3 and 7-9. Journal of Educational Psychology, 105, 535-551. https://doi.org/10.1037/a0030417

Kärnä, A., Voeten, M., Little, T. D., Poskiparta, E., Kaljonen, A., \& Salmivalli, C. (2011). Alarge-scale evaluation of the KiVa antibullying program: grades 4-6. Child Development, 82, 311-330. https://doi.org/10.1111/j.1467-8624.2010.01557.x

Kawamura, S., \& Tagami, F. (1997). Development of a scale to detect bullying and isolation in class. Japanese Journal of Counseling Science, 30, 112-120.

Klomek, A. B., Sourander, A., \& Gould, M. (2010). The association of suicide and bullying in childhood to young adulthood: A review of cross-sectional and longitudinal research findings. Canadian Journal of Psychiatry, 55, 282-288. https://doi.org/10.1177/070674371005500503

Olweus, D. (1993). Bullying at school: What we know and what we can do. Cambridge: Blackwell.

Olweus, D. (1994). Bullying at school: Basic facts and effects of a school based intervention program. Journal of Child Psychology and Psychiatry, 35, 1171-1190. https://doi.org/10.1111/j.1469-7610.1994.tb01229.x

Paulhus, D. L. (1983). Two-component models of socially desirable responding. Journal of Personality and Social Psychology, 46, 598-609. https://doi.org/10.1037/0022-3514.46.3.598

Salmivalli, C., \& Poskiparta, E. (2012). KiVa antibullying program: Overview of evaluation studies based on a randomized controlled trial and national rollout in Finland. International Journal of Conflict and Violence, 6 , 294-302. http://dx.doi.org/ 10.4119/UNIBI/ijcv.247

Strohmeier, D., Hoffmann, C., Schiller, E. M., Stefanek, E., \& Spiel, C. (2012). ViSC Social Competence Program. New Directions for Youth Development, 133, 71-84. https://doi.org/10.1002/yd.20008

The Committee for Children. (1986). Second Step. Seattle, WA: Author.

Uchida, K., Fukuda, E., \& Yamasaki, K. (2014). Development of the Implicit Positive and Negative Affect Test for Children (IPANAT-C): A study on the reliability and validity of the first version. Research Bulletin of Naruto University of Education, 29, 160-168.

Uchida, K., Yamasaki, K., \& Sasaki, M. (2014). Attractive, regularly-implementable universal prevention education program for health and adjustment in schools: An Innovation from Japan. Procedia - Social and Behavioral Sciences, 116, 754-764. https://doi.org/10.1016/j.sbspro.2014.01.293

Wang, M. C., Haertel, G. D., \& Walberg, H. J. (1997). Learning influences. In H. H. Walberg \& G. D. Haerte1 (Eds.), Psychology and educational practice (pp. 199-211). Berkeley, CA: McCatchan.

Yamasaki, K. (2016). The program for bullying prevention. Unpublished manuscript, Naruto University of Education.

Yamasaki, K., Murakami, Y., Yokoshima, T., \& Uchida, K. (2015). Effectiveness of a school-based universal prevention program for enhancing self-confidence: Considering the extended effects associated with achievement of the main purposes of the program. International Journal of Applied Psychology, 5, 152-159. http://article.sapub.org/10.5923.j.ijap.20150506.02.html

Yokoshima, T., Uchiyama, Y., Uchida, K., \& Yamasaki, K. (2017). Development of the paper and pencil version of Self-Esteem Implicit Association Test for Children (SE-IAT-C): Investigation of the reliability and validity utilizing Rosenberg's Self-Esteem Scale and assessment of children by teachers. Journal for the Science of Schooling, 18, $1-13$.

\section{Copyrights}

Copyright for this article is retained by the author(s), with first publication rights granted to the journal.

This is an open-access article distributed under the terms and conditions of the Creative Commons Attribution license which permits unrestricted use, distribution, and reproduction in any medium, provided the original work is properly cited. 